See discussions, stats, and author profiles for this publication at: https://www.researchgate.net/publication/341492752

Overexpression of a novel cytochrome P450 monooxygenase gene, CYP704B1, from Panax ginseng increase biomass of reproductive tissues in transgenic Arabidopsis

Article in Molecular Biology Reports · June 2020

DOI: $10.1007 /$ s11033-020-05528-x

0

10 authors, including:

Jeniffer Silva

The Bridge Biofoundry

19 PUBLICATIONS 60 CITATIONS

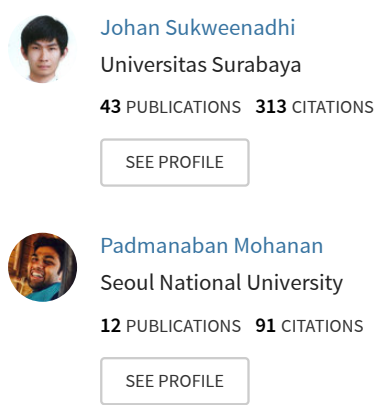

Some of the authors of this publication are also working on these related projects:

Project Food safety View project

Project Root biology View project 


\title{
Overexpression of a novel cytochrome P450 monooxygenase gene, CYP704B1, from Panax ginseng increase biomass of reproductive tissues in transgenic Arabidopsis
}

\author{
Jeniffer Silva ${ }^{1}$. Johan Sukweenadhi ${ }^{1}$. Davaajargal Myagmarjav ${ }^{1} \cdot$ Padmanaban Mohanan $^{1}$. Junping $\mathrm{Yu}^{2}$. \\ Jianxin $\mathrm{Shi}^{2} \cdot \mathrm{Ki}$-Hong Jung ${ }^{3} \cdot$ Dabing Zhang ${ }^{2,3} \cdot$ Deok-Chun Yang ${ }^{1} \cdot$ Yu-Jin Kim ${ }^{1,3}$
}

Received: 7 November 2019 / Accepted: 14 May 2020

(c) Springer Nature B.V. 2020

\begin{abstract}
Cytochrome P450 monooxygenase 704B (CYP704B), a member of the CYP86 clan, was found to be needed in Arabidopsis and rice to biosynthesize precursors of sporopollenin through oxidizing fatty acids. In the present study, we cloned and characterized a CYP704B gene in Panax ginseng, named PgCYP704B1. It shared high sequence identity (98-99\%) with CYP704 of Arabidopsis, Theobroma cacao, and Morus notabilis. The phylogenetic comparison of ginseng and higher plants between the members of $C Y P 86$ clan revealed that ginseng $C Y P 704$ was categorized as a group of $C Y P 704 B$ with dicot plants. The expression of $P g C Y P 704 B 1$ is low in the stem, leaf, and fruit, and high in flower buds, particularly detected in the young gametic cell and tapetum layer of the developing anther. Arabidopsis plants overexpressing $P g C Y P 704 B 1$ improved plant biomass such as plant height, siliques and seed number and size. A cytological observation by transverse and longitudinal semi-thin sections of the siliques cuticles revealed that the cell length increased. Furthermore a chemical analysis showed that $P g C Y P 704 B 1$ ox lines increased their cutin monomers contents in the siliques. Our results suggest that $P g C Y P 704 B 1$ has a conserved role during male reproduction for fatty acid biosynthesis and its overexpression increases cutin monomers in siliques that eventually could be used for seed production.
\end{abstract}

Keywords Panax ginseng $\cdot$ Cytochrome P450 $\cdot$ Overexpressing plants $\cdot$ PgCYP704B1 $\cdot$ Reproduction $\cdot$ Fatty acid $\cdot$ Seed yield · Biomass

Electronic supplementary material The online version of this article (https://doi.org/10.1007/s11033-020-05528-x) contains supplementary material, which is available to authorized users.

Deok-Chun Yang

dcyang@khu.ac.kr

$\triangle$ Yu-Jin Kim yujinkim@khu.ac.kr

1 Graduate School of Biotechnology and Department of Oriental Medicinal Biotechnology, College of Life Science, Kyung Hee University, Yongin 446-701, Korea

2 Joint International Research Laboratory of Metabolic \& Developmental Sciences, Shanghai Jiao Tong UniversityUniversity of Adelaide Joint Centre for Agriculture and Health, State Key Laboratory of Hybrid Rice, School of Life Sciences and Biotechnology, Shanghai Jiao Tong University, Shanghai, China

3 Graduate School of Biotechnology and Crop Biotech Institute, Kyung Hee University, Yongin 446-701, Korea

\section{Introduction}

Cytochrome P450s (CYPs) are conserved heme-thiolate monooxygenases throughout the plant kingdom that are associated in the synthesis of essential backbone structures characteristic of distinct primary and secondary metabolite groups [1-3]. There are 244 CYP genes in the Arabidopsis genome, divided into nine clans, covering 65 families, based on their phylogeny [4]. CYPs divide into three groups based on the biochemistry catalyzed [5]. The first group biosynthesizes organic compounds and comprises clans 51, 97, 710 , and 711 . The second group catalyze the biosynthesis of secondary metabolites, and comprises clan 71 . The third group biosynthesizes plant hormones and fatty acids, and comprises clans $72,74,85$, and 86 [4].

Regarding plant reproductive development, CYP704B family belongs to the clan CYP86, reported to be involved in the $\omega$-hydroxylation of long-chain fatty acids essential for pollen wall's exine formation, and particularly expressed 
during young microspore stage of the developing anther. Catalysis of $\omega$-hydroxylated long-chain fatty acids, lipids and their derivatives, including fatty acids, waxes [6, 7], and phospholipids $[8,9]$, are important components for development of pollen wall [10-12]. Altered exine of pollen wall was observed in mutants of Arabidopsis CYP704B1 [11], Brassica napus CYP704B1 [13] and rice CYP704B2 [12]. However, rice $C Y P 704 B 2$, besides the altered pollen exine, it showed undeveloped anther cuticle and male sterile phenotype [12]. Further studies in other plants will help to elucidate diversified $C Y P 704 B$ function regarding plant reproductive development.

Panax ginseng is a slow-growing perennial herb that has been cultivated for its highly valued root for medicinal purposes since 5000 years ago $[14,15]$. In the third year of growth, $P$. ginseng flowers and, usually, after four years of cultivation the roots are harvested $[15,16]$. Attempts to increase ginseng yield and amounts of ginsenosides have been done by developing ginseng hybrids, and although they display heterosis, F1 hybrid plants showed male sterility derived from pollen defects at the young microspores stage [16]. Previously we studied and described the morphogenesis of anther and carpel at a cytological level to comprehend and specify $P$. ginseng reproductive developmental phases $[17,18]$. Despite the importance of ginseng reproductive development, studies on functional gene analysis and molecular regulation remains scarce. In the research presented here, we isolated and cloned $C Y P 704 B 1$ gene from $P$. ginseng, $P g C Y P 704 B 1$, expressed highly in flower bud, during anther reproductive development. Overexpression of $P g C Y P 704 B 1$ in Arabidopsis showed improved plant biomass in terms of seed yield, potentially caused by the accumulation of saturated fatty acids and 2-hydroxy fatty acids in siliques. Our results suggest that $P g C Y P 704 B 1$ has a conserved role during male reproduction and also boosts the accumulation of fatty acids helping to improve seed yield.

\section{Materials and methods}

\section{Plant materials and growth conditions}

Columbia ecotype (CS60000) of Arabidopsis thaliana was used as a system model. Seeds were surface sterilized with $70 \%$ ethanol for $1 \mathrm{~min}$. Then with 50\% sodium hypochlorite for $5 \mathrm{~min}$. Then, washed thoroughly five times with distilled water. Sterilized-seeds were sown on half-strength Murashige and Skoog medium (Duchefa Biocheme) containing $1 \%$ sucrose, $0.8 \%(\mathrm{w} / \mathrm{v})$ agar, and $\mathrm{pH}$ 5.7. Under long-day photoperiod of $16 \mathrm{~h}$ light and $8 \mathrm{~h}$ dark at $23{ }^{\circ} \mathrm{C}$, 3 -day-old cold-treated seeds were germinated. The ginseng (Panax ginseng) plant organs (root body, stem, leaf, flower bud, fruit) were acquired from the Ginseng Bank in South
Korea. Transformants were screened on hygromycin $(50 \mu \mathrm{g} /$ $\mathrm{mL}$ )-selective medium plates. Under the same light/dark conditions 10-day-old seedlings were transplanted to soil and cultivated for 5 weeks.

\section{Identification of PgCYP704B1 gene and sequence analysis}

To obtain a full-length coding sequence of $P g C Y P 704 B 1$ gene, homologous sequences of CYP704 EST were searched against the SNU Genome database (kindly provided by Prof. Tae-Jin Yang, Seoul National University) using a BLASTX algorithm. A pTriplEx phagemid for CYP704 cDNA was excised from the $\lambda$ pTriplEx 2 and used as a template for sequence analysis. DNASIS program was used to analyze nucleotide and amino acid sequence (Hitachi, Japan).

The amino acid sequence of $P g C Y P 704 B 1$ was utilized to search for homologous proteins via BLAST network services at the NCBI. Sequence alignment was done using Clustal $\mathrm{X}$ and the subcellular localization for $\mathrm{N}$-terminal was predicted by psortb (https://www.psort.org/psortb/) [19]. The subcellular target of the transit peptide was identified by Predotar v. 1.03 (https://urgi.versailles.inra.fr/predotar/predo tar.html) [20]. A neighbor-joining tree was constructed with MEGA4 software, using the reliability of each node established by the bootstrap method. A 3D model was prepared on a SWISS-MODEL Workspace in automated mode [21] using CYP704 as a template. The generated 3D structure was visualized using the UCSF Chimera package. The hydropathy value was calculated using the method [22] and the secondary structures were evaluated using Multiple Alignment (SOPMA) self-optimized prediction [23]. The estimation of protein characteristics was evaluated using ProtParam [24].

\section{Vector construction and Arabidopsis transformation}

The $C Y P 704$ gene was amplified from $P$. ginseng cDNA library and cloned into $K p n I$ and SmaI sites of the pCAMBIA1390 vector containing the Cauliflower Mosaic Virus $35 \mathrm{~S}$ promoter and the yellow fluorescent protein (YFP). Before plant transformation, we verified nucleotide sequencing of the transgene construct. Agrobacterium tumefaciens C58C1 (pMP90) [25] transformants comprising pCAMBIA1390 plasmids with $C Y P 704 B 1$ were tested on a $50 \mathrm{mg} / \mathrm{L}$ kanamycin solid YEP medium. The transformation of plasmids into A. tumefaciens $\mathrm{C} 58 \mathrm{C} 1$ was confirmed by PCR using $P g C Y P 704 B 1$-specific primers after plasmids were isolated from kanamycin-resistant $\mathrm{C} 58 \mathrm{C} 1$ colonies. The construct was transformed into Arabidopsis using A. tumefaciens $\mathrm{C} 58 \mathrm{C} 1$. The insertion of transgenes into the transformants was confirmed by PCR. Homozygous plants with a 3:1 segregation ratio on antibiotic plates were selected for additional analyses. Among several T2 independent lines, 
two selected lines were further analyzed for statistical and metabolite analysis.

\section{Subcellular localization}

Leica TCS SP5 confocal laser scanning microscope (Leica Microsystems (UK) Ltd) was used to observe fluorescence (YFP excitation collected at 520-600 nm). The images were processed using the Leica TCS SP5 software (Leica Microsystems (UK) Ltd).

\section{RNA isolation and semi-quantitative RT-PCR analysis}

Total RNA extraction from frozen samples was performed using RNeasy mini kit (Qiagen, Valencia, CA, USA). $1 \mu \mathrm{g}$ of total RNA was used for cDNA synthesis. For semi qRTPCR, specific primers for $P g C Y P 704 B 1$ (F-5'-CAG TCC CTC AGG ATC CAA AA-3' and R-5'-CAA GGC AAA TCC TAG GAC CA-3') and a constitutively expressed Ginseng actin gene (F-5'-CGT GAT CTT ACA GAT AGC TTG ATG A-3'and R-5'-AGA GAA GCT AAG ATT GAT CCT CC-3') were used, with the following program: $4 \mathrm{~min}$ at $95{ }^{\circ} \mathrm{C}$; followed 33 cycles of $95{ }^{\circ} \mathrm{C}$ for $30 \mathrm{~s} ; 54{ }^{\circ} \mathrm{C}$ for $30 \mathrm{~s}$, $72{ }^{\circ} \mathrm{C}$ for $20 \mathrm{~s}$; and a final extension of $72{ }^{\circ} \mathrm{C} 7 \mathrm{~min}$. The signal instensities were measured with ImageJ 1.50i [26].

\section{RNA in situ hybridization}

Different developmental stages of flowers were collected and fixed in formalin-acetic acid alcohol (FAA, 50\% ethanol, $5 \%$ glacial acetic, $3.7 \%$ formaldehyde in water) at $4{ }^{\circ} \mathrm{C}$ for $16 \mathrm{~h}$. Then dehydrated on graded ethanol series $(85,90$, 95, 100\%), followed by xylene series, embedded in Paraplast Plus (Oxford Labware), and sectioned at $7 \mu \mathrm{m}$. The $P g C Y P 704 B 1$ cDNA was prepared from RNA isolated from ginseng flowers at different developmental stages and then cloned to the pJET clone vector. In vitro transcription under T7 promoter with RNA polymerase using DIG RNA labeling kit (Roche) was made for DIG-labeled anti-sense (forward, 5'-TTC ATC TAT AGA TGG AGC-3'; reverse, 5'-GCC TGA GCA AAG CAA TTC-3') and sense probes. RNA samplesDIG-labeled were made according to the manufacturer's guidelines using DIG RNA labeling kit (SP6/T7) (Roche, Mannheim, Germany).

A sense probe was used as a negative control. RNA hybridization and immunological detection of the hybridized probes were performed as described [27].

\section{Histology}

Semi-thin section was performed utilizing siliques of 5 -weeks old plants, fixed in FAA. Then dehydrated on graded ethanol sequence $(70,80,90$, and $100 \%) 30$ min each step. Then embedded in KULZER's Technovit 7100 cold polymerizing resin (Heraeus Kulzer GmbH Philipp-ReisStraße 8/13, D-61273 Wehrheim/Ts) by three steps of preinfiltration, infiltration, and embedding at $45^{\circ} \mathrm{C}$ [28-30]. Then sectioned $4 \mu \mathrm{m}$ thick in an Ultratome III ultramicrotome (LBK), and stained with $0.25 \%$ toluidine blue O (Chroma Gesellshaft Shaud). Bright-field photographs of the anther and siliques sections were observed in a Nikon ECLIPSE 80i microscope.

SEM was performed using anthers that were fixed and washed as described for semi-thin section, except dehydration, instead using 20,30, 40, 50, 60, 70, 80, 90, and $100 \%$ ethanol 3 min for each step. Then the samples were dried at critical point temperature (Leica EM CPD300). Followed by $5 \mathrm{~nm}$ thick Aurum coating with a Leica EM SCD050 ion sputter. Then the Aurum-coated samples were observed in a Hitachi S3400N scanning electron microscope.

Microtome sections of resin-embedded flowers and siliques were used for lipid staining with Sudan IV as described [31, 32] with modifications. Exine observation was performed accordingly as described [11].

Pollen viability test was performed using anthers stained with Alexander staining as described [33]. Nail polished slides were sealed and observed in a Nikon ECLIPSE 80i microscope.

\section{Analysis of silique cutin monomers}

Cutin from siliques of 5-week old plants were examined as described [7] with modifications. 10-20 mg of dried siliques were dipped in $2 \mathrm{~mL}$ of chloroform $1 \mathrm{~min}$. The resulting chloroform extract was spiked with $10 \mu \mathrm{g}$ of tetracosane (Fluka) as internal standard and transferred to a new glass vial. Then the solvent was evaporated under a light stream of nitrogen. Then the compounds containing free hydroxyl and carboxyl groups were transformed to trimethysilyl ethers and esters using $20 \mu \mathrm{L}$ bis-(N, N-trimethysilyl)-tri-fluoroacetamine (Sigma-Aldrich) in $20 \mu \mathrm{L}$ pyridine for $40 \mathrm{~min}$ $70{ }^{\circ} \mathrm{C}$. The monomers were identified from their electron ionization-mass spectrometry spectra $(70 \mathrm{eV}, \mathrm{m} / \mathrm{z} 50$ to 700$)$ after GC separation (column $30 \mathrm{~m}$ X $0.32 \mathrm{~mm}$ X $0.1 \mu \mathrm{m}$ film thickness [DB-1; JandW Scientific].

The cutin monomer composition of the siliques polyesters was analyzed as described [34]. The siliques were extracted for 2 weeks in freshly added $1 \mathrm{~mL}$ of chloroform:methanol $(1: 1 \mathrm{v} / \mathrm{v})$. This step was repeated four times before the siliques were finally dried at $30^{\circ} \mathrm{C}$ for $16 \mathrm{~h}$. Then the delipidated siliques were depolymerized by transesterification in $1 \mathrm{~mL}$ of $1 \mathrm{~N}$ methanolic $\mathrm{HCL}$ at $80^{\circ} \mathrm{C}$ for $2 \mathrm{~h}$. Then added $2 \mathrm{~mL}$ of saturated $\mathrm{NaCl} / \mathrm{H}_{2} \mathrm{O}$ and $10 \mu \mathrm{g}$ of drotriacontane (Fluka) as internal standard. Then hydrophobic monomers were extracted three times with $1 \mathrm{~mL}$ of hexane. Then the organic phases were mixed, the solvent was evaporated, and 
the remaining sample was derivatized as described above. GC-MS (Agilent gas chromatograph coupled to an Agilent $5973 \mathrm{~N}$ quadrupole mass selective detector) and GC-FID (Agilent 6890 gas chromatograph) analysis were performed.

\section{Statistical analysis}

Data were analyzed with GraphPad Prism 8 (GraphPad Software, Inc., San Diego, CA, USA). All data are expressed as means \pm standard error of the mean for at least six replicates. The statistical significance of all the differences between the phenotypic traits of height, seeds-per silique, seed size, and siliques per plant, was determined using a one-way ANOVA and Kruskal-Wallis non-parametric post-hoc test. $P$ value $\leq 0.05$ was considered significant.

\section{Results}

\section{PgCYP704B1 encodes a putative cytochrome P450 hydroxylase in ginseng}

Full genomic DNA sequence of PgCYP704B1 was analyzed using the genomic DNA sequence retrieved from the database of ginseng genome (http:/im-crop.snu.ac.kr/new/ index.php). An NCBI Blast search (http:/www.ncbi.nlm.nih. gov/BLAST/) displayed the conserved superfamily P450, suggesting that $P g C Y P 704 B 1$ belongs to the P450 family. The CYP704 family belongs to the CYP86 clan of fattyacid hydroxylases, and since the CYP704 family underwent only one duplication, it divided the subfamilies CYP704A and CYP704B, predicting the differentiation between monocots and $[2,4,11]$. To gain information about the potential function of $\mathrm{PgCYP704B1}$, its protein sequence and its relatives in higher plants, including Arabidopsis [11] and rice [12], were used to build a phylogenetic tree (Fig. 1). Based on our phylogenetic comparison, $\mathrm{PgCYP704B1}$ was placed in clan 86 subfamily CYP704B, separated from the closest associated clan 71 [4]. Several members in the clan 86 have been shown to catalyze fatty acid hydroxylation [12, 35-38], and the $C Y P 704 B$ subfamily members are expressed in the reproductive organs, among plants from bryophytes to angiosperms $[12,39]$, indicating an essential and conserved function that $P g C Y P 704 B 1$ may have in fatty acid hydroxylation during plant male reproductive development. In addition, multiple sequence alignment (Fig. S1) showed that the CYP704 proteins and PgCYP704B1 contain the conserved domains such as AGRDT, TETLR; PERFW, and the FQAFPRICLG (F, G and C residues), as a common feature for CYPs functions $[4,11]$. The predicted transit peptide of PgCYP704B1 (indicated arrow in Fig. S1) is shown to be positioned at its $\mathrm{N}$-terminal with a cytoplasmic location [19] targeting endoplasmic reticulum (ER) and could function in the hydroxylation of fatty acids. Fatty acids are hydroxylated in plant cells in the ER through members of the CYP family [5, 40, 41]. To confirm the subcellular location of PgCYP704B1, we developed a translational fusion of the full-length PgCYP704B1 coding region and yellow fluorescent protein (YFP) controlled by the cauliflower mosaic virus 35 S promoter (35Spro:PgCYP704B1:YFP). As we expected, the fluorescence of 35Spro:PgCYP704B1:YFP was targeted to the ER organelle (Fig. 1b-d). Consistently, previous studies have shown that $C Y P 704 B 1$ is targeted to ER in Arabidopsis and B. napus [13, 42]. CYPs can be divided into four classes depending on how electrons from NAD(P) $\mathrm{H}$ are delivered to the catalytic site, and a typical feature of class II is to be independently anchored on the outer face of the ER by amino-terminal hydrophobic anchors [43], as also confirmed in our results (Fig. S3b). The cDNA encoding $P g C Y P 704 B 1$ has a length of $1,557 \mathrm{bp}$, encoding 518 amino acids; moreover, the $P g C Y P 704 B 1$ gene contains six exons and five introns (Fig. S2), which is a common characteristic with Arabidopsis and B. napus CYP704B1 genes [11, 13].

PgCYP704B1 hydrophobicity profile and its nearest homologs indicate that both the $\mathrm{N}$ and $\mathrm{C}$ terminals are highly conserved (Fig. S3b). The conserved domains of CYPs (AGRDT, TETLR; PERFW, and FQAFPRICLG) are hydrophobic, compatible with their place in the predicted 3D model, as they form part of the helixes (Fig. S3a). A similar number of alpha-helices, beta-turns, extended strands, and random coils (Table 1) was found on the secondary structure analysis (Fig. S3c) of PgCYP704B1 and the CYP704 proteins with close phylogenetic relationship.

\section{PgCYP704B1 is highly expressed in flower buds}

To verify the conserved function of $P g C Y P 704 B 1$ in the anther as it has been described for Arabidopsis [11], rice [12], and B. napus [13], we conducted $P g C Y P 704 B 1$ expression analysis by semi qRT-PCR utilizing ginseng tissues such as root, stem, leaf, flower buds and fruit. The transcript of $P g C Y P 704 B 1$ was expressed highly in flower buds, although expression was identified at lower intensity in stem, leaves, and fruit (Fig. 2a, Fig. S2C).

To gain insight into the spatial and temporal patterns of $P g C Y P 704 B 1$ expression in anthers, we performed in situ hybridization (Fig. 2b-d). The results showed that $P g C Y P 704 B 1$ is expressed in the tapetal cell layer and meiocytes during the anther reproductive developmental stages 3 to 5 (classification made by Kim et al. [17]). In stage 3, when the microspore mother cells initiate meiotic division, the maximum amount of $P g C Y P 704 B 1$ in the tapetum and dyads was observed. The hybridization weakened to tapetal cells, tetrads, and microspores after the development of tetrads at stage 4 . For control hybridization, a sense probe was used (Fig. 2e). 
A

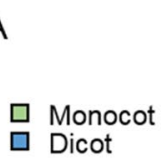

Dicot

100

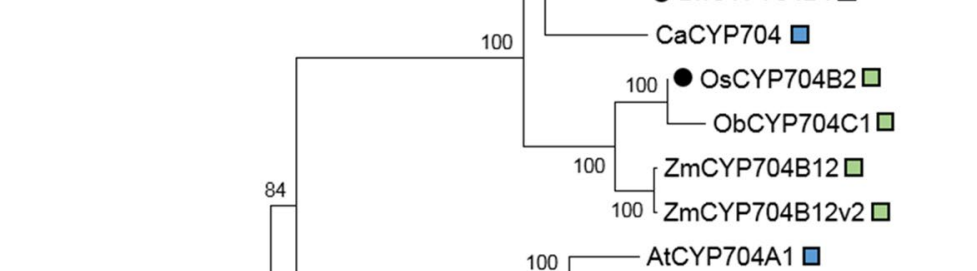

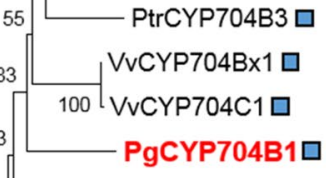

- AtCYP704B1口

100

- AtCYP704A2

65

99
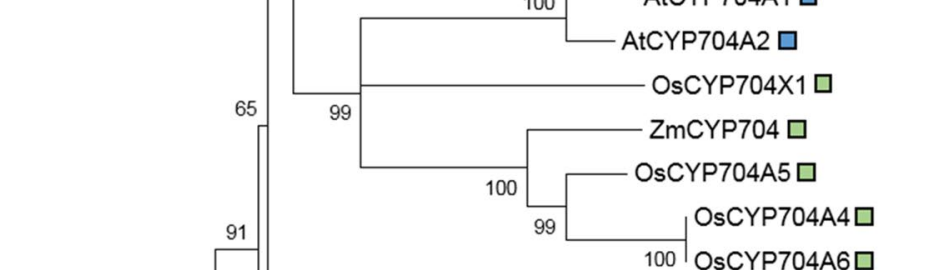

99

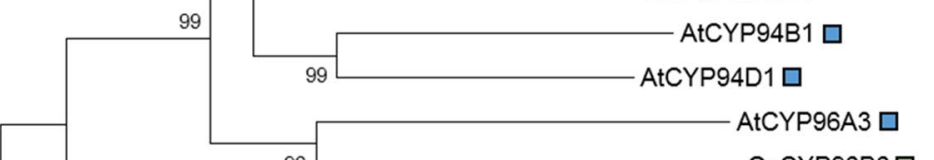
OsCYP96B6口

OsCYP97C2ם

$\mathrm{V} v \mathrm{CYP78A3 \square}$

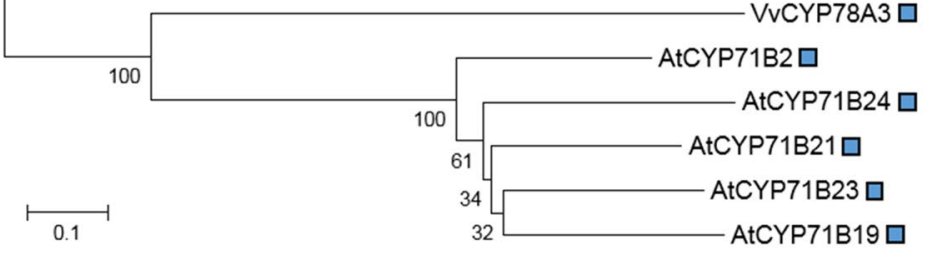

Fig. 1 Phylogenic analysis of $P g C Y P 704 B 1$. a A neighbor-joining method analysis was performed using MEGA 4 based on the Table S1. Bootstrap values are percentage of 1000 replicates. The scale bar shows 0.1 amino acid substitutions per site. Black dots show reported $C Y P 704 B$ genes. Subcellular localization of $P g C Y P 704 B 1$ by confocal laser scanning microscopy images of $7 \mathrm{~d}$-old seedlings roots in transgenic lines expressing 35Spro:PgCYP704-YFP in endoplasmic reticulum (ER), b YFP fluorescence, $\mathbf{c}$ bright field, and d merged images. Bars; b-d $100 \mathrm{~mm}$
Table 1 Secondary structure characteristics of ginseng CYP704B1 and other plants with close phylogenetic relationship

\begin{tabular}{lllcc}
\hline Protein & Alpha-helices & Beta-turns & $\begin{array}{l}\text { Extended } \\
\text { strands }\end{array}$ & Random coils \\
\hline PgCYP704B1 & 219 & 41 & 111 & 146 \\
$T c C Y P 704 B$ 1 isoform1 [EOY01870] & 250 & 41 & 95 & 149 \\
$T c C Y P 704 B$ 1 isoform2 [EOY01871] & 249 & 41 & 95 & 152 \\
$M n C Y P 704 C 1$ [EXB92426] & 259 & 36 & 96 & 174 \\
$A t C Y P 704 B 1$ [OAP12978] & 242 & 38 & 100 & 144 \\
$C c C Y P 704 C 1$ [KYP54385] & 266 & 36 & 92 & 121 \\
\hline
\end{tabular}




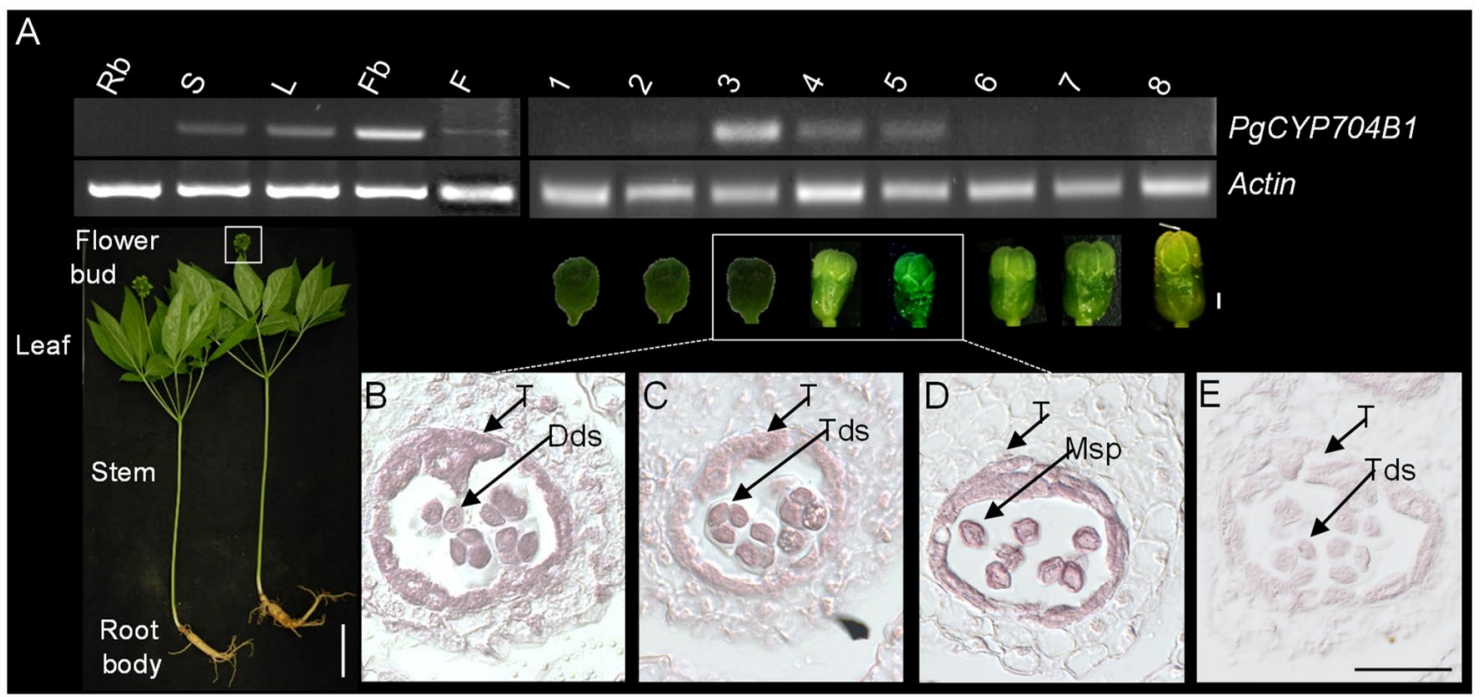

Fig. 2 Expression pattern of $P g C Y P 704 B 1$. a Spatial and temporal expression analysis of $P g C Y P 704 B 1$ transcript in selected tissues and anther development by semi qRT-PCR. Tissues from 5 year-old ginseng and flowers from 14 to 24 days after sprouting were analyzed for the presence of $P g C Y P 704 B 1$. Ginseng actin (Pg Actin) expression was used as a control. $\mathrm{Rb}$, root body; $\mathrm{S}$, stem; $\mathrm{L}$, leaf; $\mathrm{Fb}$, flower bud, and F, fruit; 1 , stage $1 ; 2$, stage $2 ; 3$, stage $3 ; 4$, stage 4 ;

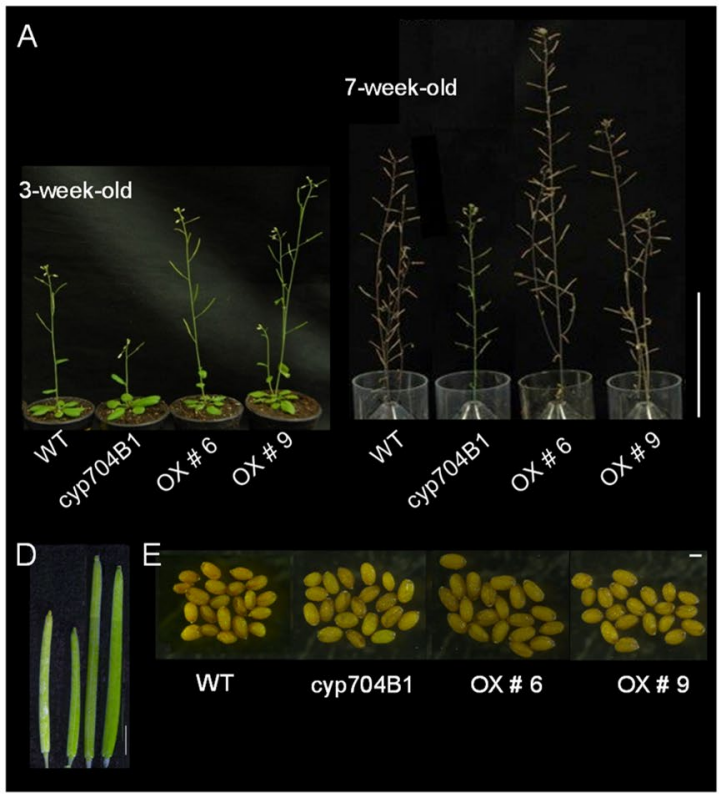

Fig. 3 Overexpression of $P g C Y P 704 B 1$ in Arabidopsis improves biomass. Greater growth in $\mathbf{a}, \mathbf{b}$ height, $\mathbf{c}$ siliques per plant, $\mathbf{d}$ siliques size, $\mathbf{e}$, $\mathbf{f}$ seed size, and $\mathbf{g}$ seeds per silique. Bars show mean expres-

\section{Overexpression of PgCYP704B1 improves plant productivity in transgenic Arabidopsis}

Due to difficulties in obtaining transgenic regenerated $P$. ginseng plants, we observed the effect of overexpressing
5, stage $5 ; 6$, stage $6 ; 7$, stage $7 ; 8$, stage 8 . b-d RNA in situ analysis of $P g C Y P 704 B 1$ in anthers. The anthers at stage 3 (b), 4 (c), and 5 (d) showing strong signal of $P g C Y P 704 B 1$ in tapetal cells and microspores; e The sense probe produces no signal at stage 4 (control). $D d s$, dyads; $M s p$, microspore; $T$, tapetum; $T d s$, tetrads. Bars; a $10 \mathrm{~cm}$ and $1 \mathrm{~mm}, \mathbf{b}-\mathbf{d} 50 \mu \mathrm{m}$

B

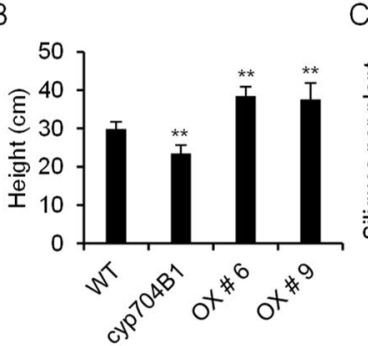

C

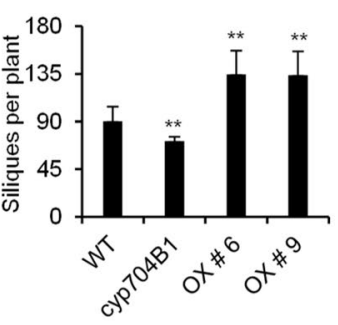

$\mathrm{F}$

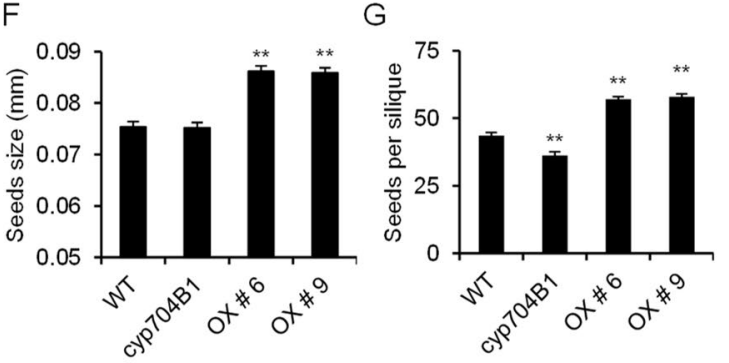

sion levels \pm SE. $W T$, Wild-type; cyp704B1, mutant; $O X \# 6, P g C Y P$ 704Blox \# 6; OX \# 9, PgCYP704Blox \# 9. *P <0.05. Bars; a $10 \mathrm{~cm}$, d $5 \mathrm{~mm}$ e-h $500 \mu \mathrm{m}$

PgCYP704B1 in transgenis Arabidopsis (PgCYP704Blox). We examined plant biomass-related characteristics such as plant height, number and size of siliques and seeds. $P g C Y P 704 B 1$ ox produced $21 \%$ taller plants compared with wild-type and mutant (Fig. 3a, b). As observed in 
$P g C Y P 704 B 1$ ox, the siliques increased $43.25 \%$ in number compared with wild-type and mutant (Fig. 3c, d). $\mathrm{PgCYP}$ $704 B$ lox increased $10 \%$ in seed size and $45.25 \%$ in average yield compared with those of control (Fig. $3 \mathrm{e}-\mathrm{g}$ ).

In addition we stained mature anthers with lipophilic dye Sudan IV to observe the cuticular lipid deposition [31, 32]. Compared to wild-type, anthers of cyp $704 B 1$ and $P g C Y P$ $704 B$ lox showed increased lipidic compounds in the anther epidermal layer, and an opposite effect on the pollen wall (Fig. S4). As cyp704B1 also shows high lipidic compounds, it confirms the conserved function of this $C Y P 704 B$ is the biosynthesis of lipidic precursors essential for anther reproductive development.

\section{PgCYP704B1 can functionally complement the Arabidopsis cyp704B1 mutant}

The Arabidopsis cyp704B1 was reported to show impaired pollen walls lacking a normal exine layer that displays a stripped surface called zebra phenotype [11]. To determine whether $P g C Y P 704 B 1$ was able to complement the Arabidopsis cyp $704 B 1$, we performed a complementation assay by reciprocal hand pollination of $\mathrm{PgCYP704B10x}$ with cyp $704 B 1$. The stable incorporation of the $P g C Y P 704 B 1$ gene into cyp704B1 was confirmed by PCR (Fig. S5). To observe the anthers and pollen phenotype, we used Alexander staining, semi-thin cross sections, Auramine O, and SEM. Pollen viability showed to not be affected, we assume that this recovery is due to PgCYP704B1 being involved in the sporopollenin biosynthesis and lipidic precursors, that could be stably co-transmitted to progeny plants and that it co-segregated with the introduced DNA. Although the anther of $P g C Y P 704 B$ lox looks similar to the wild type and cyp704B1, the number of pollen grains increase and exhibits a compacted arrangement in $P g C Y P 704 B 1$ ox (Fig. S6a-d). To characterize the alterations of the PgCYP704Blox complementary lines we used Alexander staining showing that the anthers where reduced in size, in both height and width, but viable pollen (Fig. S7 a, b). Compared with wild-type, the anthers of $P g C Y P 704 B 1$ ox and cyp704B 1 exhibited bigger pollen grains at stage 14 [44] (Fig. S6e-h). Laser scanning confocal microscopy (LSCM) of Auramine O-stained $P g C Y P 704 B 1$ ox exhibits a more tightly organized exine architecture compared to wild-type, further we also confirmed that cyp $704 B 1$ exhibits no exine membrane as Dobritsa et al. [11] reported (Fig. S6i-1). PgCYP704B1 overexpression complemented the zebra pollen phenotype of cyp704B1 checked by Auramine O (Fig. S7c, d), confirming the functional ortholog of $P g C Y P 704 B 1$ to $C Y P 704 B 1$ of Arabidopsis. Examination by SEM analysis showed that the outer surface of the pollen had a denser exine compared to wild-type and cyp704B1 (Fig. S6m-p).
Complementary- $\mathrm{PgCYP704B}$ lox exhibits a normal pollen exine (Fig. S7g-h). Moreover, SEM analysis of anthers showed similar surface structure compared to wild-type (Fig. S6q-x). Complementary-PgCYP704B1 ox exhibits no difference on the anther surface (Fig. $S 7 g-j$ ). Taken together, these results indicate that the overexpression of $P g C Y P 704 B 1$ significantly affected pollen number and exine development.

\section{PgCYP704B1 promotes significant silique cell elongation and affects fatty acids contents in transgenic Arabidopsis}

We carried out light microscopic analysis of semi-thin sections to further observe the phenotype of the elongated siliques. The results revealed that $P g C Y P 704 B 1$ ox exhibited longer exocarp cells observed by longitudinal sections and increased number of sclerenchyma cells observed by transverse sections in comparison with wild-type and cyp704B1 (Fig. S8).

The cuticle is a hydrophobic layer, that coats the surface of the aerial organs such as leaves, stems, flowers, and fruits [12]. The cuticle layer functions not only in the interaction with the environment but also in plant development and growth [45]. All cuticles are biopolymers composed of two classes of lipophilic constituents, cutin and waxes [12, 46-50]. Because of the elongated siliques phenotype of $\mathrm{PgCYP704B1}$ ox and that the exocarp is made of cutin, we further performed gas chromatography-mass spectrometry (GC-MS) and gas chromatography-flame ionization detection (GC-FID). The levels of cutin monomers were found to increase up to 1.34 times of increment in $\mathrm{PgCYP704B10x}$ in comparison with wild-type (Fig. 4a). The overexpression of $P g C Y P 704 B 1$ significantly promoted the accumulation of saturated fatty acids such as C18:0 (1.5 times), C18:1 (1.8 times), C18:2 (1.6 times), C18:3 (1.8 times), C20:2 (2.1 times), and C24:0 (1.1 times) (Fig. 4b). The contents of 2-hydroxy fatty acids also significantly increased for C16:0 (1.2 times), C22:0 (1.5), C24:0 (1.2 times), C24:1 (1.2 times), C25:0 (1.9 times), and C26:0 (1.2 times) (Fig. 4c). Compared with the reported AtCYP704, OsCYP704, and BnCYP704 the common effect with $P g C Y P 704 B 1$ is the increment of longchain fatty acids. However $P g C Y P 704 B 1$ is also increasing very long-chain fatty acids, moreover $\mathrm{PgCYP704B1}$ did not show any increment of dicarboxylic fatty acids, terminal-hydroxy fatty acids, and alcohols (Fig. 4d-f). These data indicate that overexpression of $P g C Y P 704 B 1$ in Arabidopsis synthesizes and promotes the accumulation of cutin in siliques. 

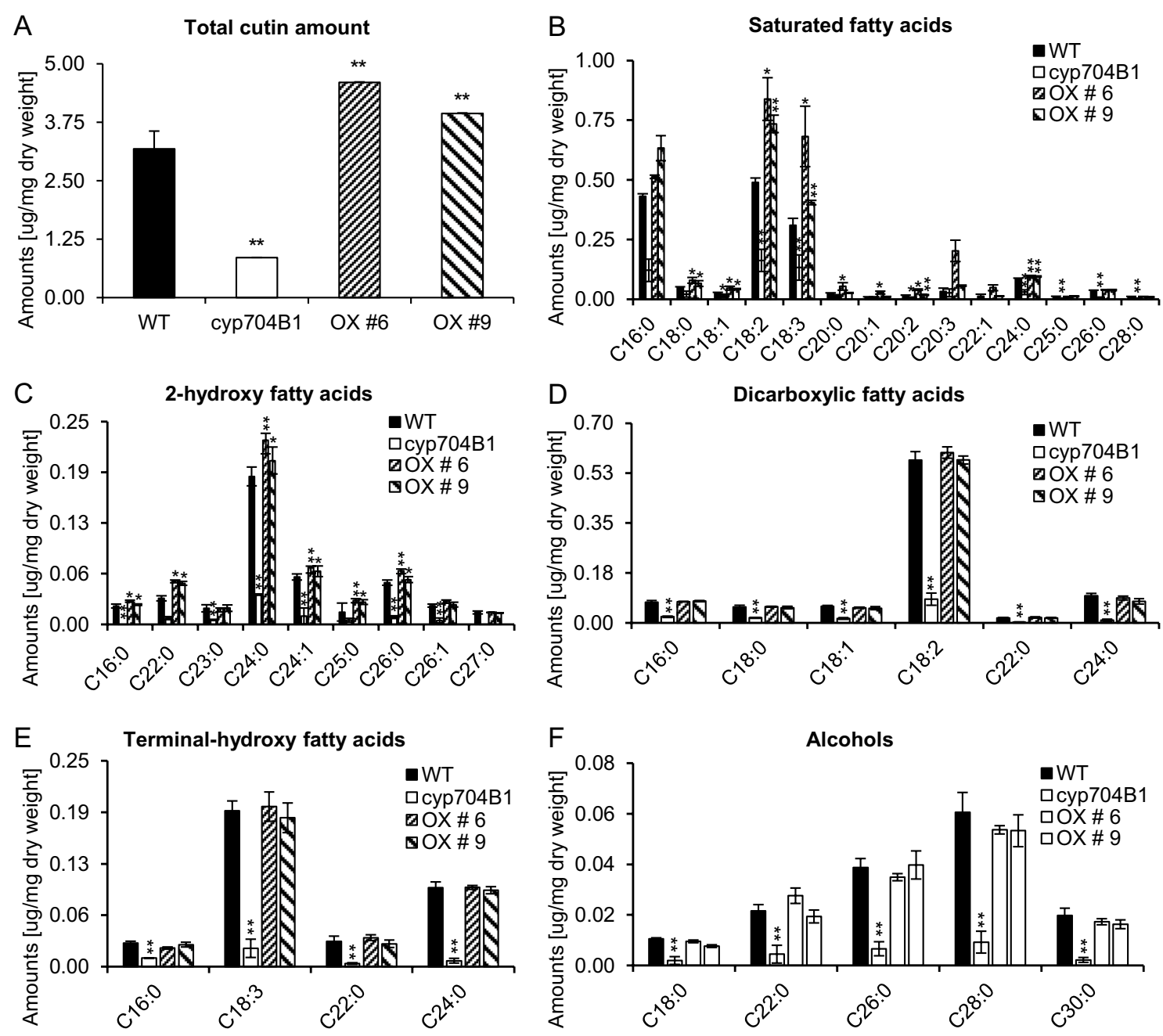

Fig. 4 Chemical analysis of siliques cutin monomers in the wild-type, cyp704B1, and PgCYP704ox lines by GC-MS and GC-FID. a Total cutin amount per milligram of dry weight $(\mu \mathrm{g} / \mathrm{mg})$. b Saturated fatty acids per milligram of dry weight $(\mu \mathrm{g} / \mathrm{mg})$. c 2-hydroxy fatty acids per milligram of dry weight $(\mu \mathrm{g} / \mathrm{mg})$. d Dicarboxylic fatty acids per

\section{Discussion}

\section{PgCYP704B1 is ortholog of AtCYP704B1 and it is highly expressed in the developing anther}

$P g C Y P 704 B 1$ is ortholog of AtCYP704B1 (Fig. 1, S1) and it contains the four CYPs conserved domains (Fig. S1) indispensable for CYP functions [3, 11]. First, a Thrcontaining binding pocket for molecular oxygen required in catalysis (AGRDT). Second, the E-R-R triade, using the consensus TETLR and PERW, generally thought to be involved in locking the heme pocket into position to assure stabilization of the conserved core structure. And lastly, the heme-binding domain (FQAGPRICLG) in the C terminus. milligram of dry weight $(\mu \mathrm{g} / \mathrm{mg})$. e Terminal-hydroxy fatty acids per milligram of dry weight $(\mu \mathrm{g} / \mathrm{mg})$. f Alcohols per milligram of dry weight $(\mu \mathrm{g} / \mathrm{mg})$. The values indicate means of five biological replicates $\pm \mathrm{SD} . * \mathrm{P}<0.05 ; * * \mathrm{P}<0.01$

Both $P g C Y P 704 B 1$ and AtCYP704B1, show a conserved function during anther reproductive development for sporopollenin biosynthesis [11] (Fig. 2). In accordance, $P g C Y P 704 B 1$ expression in developing anther shows common tendencies with Arabidopsis, rice, and B. napus [11-13] at developing young microspores stage (Fig. 2). Although $C Y P 704 B$ expression in the developing anther slightly varies among $P$. ginseng, Arabidopsis rice, and $B$. napus. AtCYP704B1 starts at the young microspore and it fades at vacuolation [11] and $O s C Y P 704 B 2$ starts at the tetrad and it fades at mitosis I [12]. Whereas BnCYP704 starts at early meiosis and it fades at pollen maturation [13]. $P g C Y P 704 B 1$ starts at cell division (early meiosis) and it peaks its expression at meiosis fading at young microspore (stage 3, Fig. 2a). Suggesting that the tapetum might be 
metabolically overactivated, thus increases meiotic division, and ultimately $\mathrm{PgCYP} 704 \mathrm{~B}$ lox produces more number of pollen grains (Fig. S7).

$P g C Y P 704 B 1$ complemented the zebra pollen phenotype of $c y p 704 B 1$ (Fig. S7c, d), confirming the functional ortholog of PgCYP704B1 to CYP704B1 of Arabidopsis and that $P g C Y P 704 B 1$ is involved in fatty acid hydroxylation and is required for pollen exine formation.

\section{PgCYP704B1 contributes to improve biomass of reproductive tissues and affects fatty acid contents}

PgCYP704B1 overexpression in transgenic Arabidopsis improved plant biomass as observed in plant height, size and number of siliques and seeds. The increases were $21 \%$ in plant height, $42.75 \%$ in siliques size, $43.25 \%$ in siliques number, $10 \%$ in seed size, and $45.25 \%$ in seed yield, compared to wild-type (Fig. 3). Consistently, PgCYP704B1 expression was observed at lower intensity in the fruits (Fig. 2a), the phenotype of $\mathrm{PgCYP704B10x}$ displayed longer siliques and longer exocarp cells in the siliques of the transgenic Arabidopsis (Fig. 3), and the long-chain and very long-chain fatty acids were also increased (Fig. 4). It is well known that sporopollenin is a highly cross-linked biopolymer of hydroxylated fatty acids, aliphatic compounds, and phenolics [5, 11, 51-62]. In rice, sporopollenin precursors are delivered from the tapetum in the form of Ubisch bodies [63]. The tapetum is responsible for the biosynthesis of sporopollenin building blocks in the post-tetrad stage [63]. According to Wang et al. [63], the synthesis of sporopollenin precursors involves eight vital enzymes in Arabidopsis, including ACYL-CoA SYNTHETASE5 (ACOS5) which catalyzes mid-/long-chain fatty acids into fatty acyl-CoA, then they are hydroxylated by $C Y P 703 A 2$ and $C Y P 704 B 1$. POLYKETIDE SYNTHASE A (PSKA) and PSKB catalyze the hydroxylated products into triketides and tetraketides $\alpha$-pyrones, conforming the substrates of TETRAKETIDE $\alpha$-PYRONE REDUCTASE1 (TKPRI) and TKPR2. And MALE STERILE2 (MS2) catalyzes the protein of palmitoyl acyl carrier into a fatty alcohol as a fatty acyl reductase $[5,11,53,54,57,59,64,65]$. The resulting precursors of sporopollenin are synthesized in the tapetum and transferred by the ATP-binding cassette transporter superfamily member ( $A B C G 26)$ to the anther locule [63, 66]. Arabidopsis ABCG26 has been reported to restore fertility in terms of seed yields [66] and is also predicted to transport synthesized sporopollenin precursors to the anther locule [63].

Taken together, this close association of $A B C G 26$ with $C Y P 704 B 1$, the fact that $A B C G 26$ regulates seed yield [66], and that $P g C Y P 704 B 1$ overexpression showed increased lipidic compounds and increased plant biomass (Fig. 3), leads to hypothesize that $P g C Y P 704 B 1$ overexpression

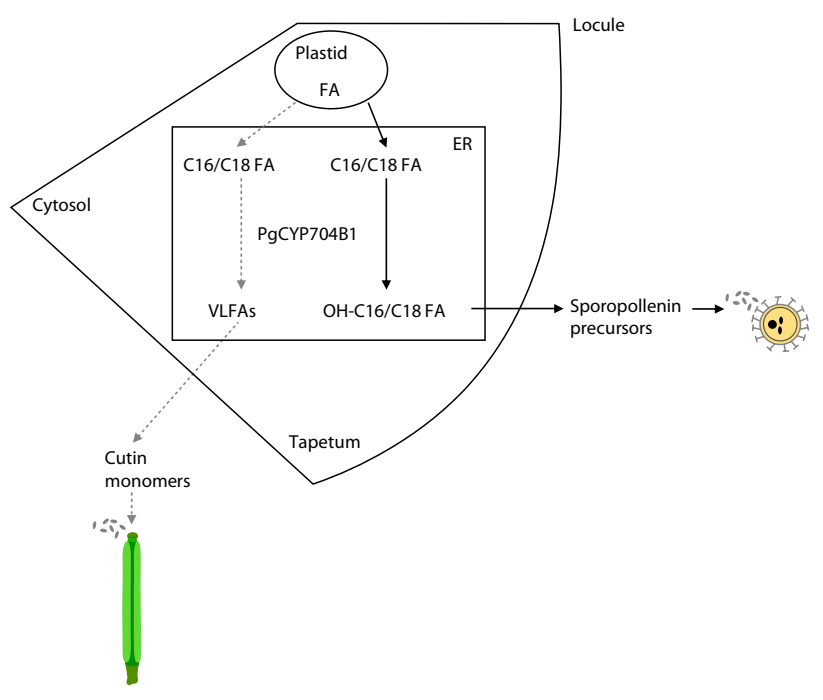

Fig. 5 Hypothetical model of the role of $P g C Y P 704 B 1$ in improving yield in reproductive tissues. Fatty acids produced in the plastid are transferred into the ER. Then they are synthesized to a maximum of C18 and C28 (VLFAs) in length. The resulting hydroxylated fatty acids are then transported to either use as precursors for sporopollenin in pollen, or as cutin monomers in siliques

might mediate plant biomass production in terms of fruits and seeds, synthesizing essential components of the anther and silique cuticle (Fig. 5), nevertheless this hypothesis requires further assessment by future studies. It will require further investigation to find out whether $P g C Y P 704 B 1$ can directly interact with $A B C G$ protein or whether this interaction depends on other molecular players.

\section{Conclusions}

In this study, we have identified and characterized an unknown $P$. ginseng gene encoding a cytochrome $\mathrm{P} 450$ protein, which was designated $P g C Y P 704 B 1 . P g C Y P 704 B 1$ transcripts are low in the fruits and high in the flower buds, specially from the meiosis- to the young microspore-anther stages. Overexpression of $\mathrm{PgCYP704B1}$ in transgenic Arabidopsis improves plant biomass of reproductive tissues and enhances the accumulation of saturated fatty acids and 2-hydroxy fatty acids in siliques. It shows a conserved function in catalyzing $\omega$-hydroxylation of long-chain fatty acids serving as building blocks of sporopollenin during anther reproductive development, suggesting its conserved role during male reproduction; furthermore, it exhibits a diversified function regarding reproductive tissues biomass improvement, particularly for seed production.

Acknowledgements This work was supported by grants from the Basic Science Research Program, National Research 
Foundation (NRF), Ministry of Education, Republic of Korea (Grant 2016R1A6A3A11931858 to YJK), and "Cooperative Research Program for Agriculture Science and Technology Development (PJ01492202 to YJK)" Rural Development Administration, Republic of Korea.

Author contributions YJK, DCY, and DZ conceived and design the project and experiments. JS, JS, DM, PM conducted the experiments. JS, YJK and KHJ co-write the manuscript. JY contributed for cytological analysis, and JS performed the wax and cutin analysis. All authors read and approved the manuscript.

\section{Compliance with ethical standards}

Conflicts of interest No conflict of interest was reported by the authors.

\section{References}

1. Morant M, Bak S, Moller BL, Werck-Reichhart D (2003) Plant cytochromes P450: tools for pharmacology, plant protection and phytoremediation. Curr Opin Biotechnol 14:151-162

2. Nelson DR, Schuler MA, Paquette SM, Werck-Reichhart D, Bak $S$ (2004) Comparative genomics of rice and Arabidopsis. Analysis of 727 cytochrome P450 genes and pseudogenes from monocot and dicot. Plant Physiol 135:756-772

3. Werck-Reichhart D, Bak S, Paquette S (2002) Cytochromes P450. Arabidopsis Book 1:e0028. https://doi.org/10.1199/tab.0028

4. Bak S, Beisson F, Bishop G, Hamberger B, Hofer R, Paquette S, Werck-Reichhart D (2011) Cytochromes P450. Arabidopsis Book 9:e0144. https://doi.org/10.1199/tab.0144

5. Morant M, Jørgensen K, Schaller H, Pinot F, Møller BL, WerckReichhart D, Bak S (2007) CYP703 is an ancient cytochrome P450 in land plants catalyzing in-chain hydroxylation of lauric acid to provide building blocks for sporopollenin synthesis in pollen. Plant Cell 19:1473-1487

6. Jessen D, Olbrich A, Knüfer J, Krüger A, Hoppert M, Polle A, Fulda M (2011) Combined activity of LACS1 and LACS4 is required for proper pollen coat formation in Arabidopsis. Plant $\mathbf{J}$ 68:715-726

7. Jung KH, Han MJ, Lee DY, Lee YS, Schreiber L, Franke R, Faust A, Yephremov A, Saedler H, Kim YW, Hwang I, An G (2006) Wax-deficient anther1 is involved in cuticle and wax production in rice anther walls and is required for pollen development. Plant Cell 18:3015-3032

8. Flores-Tornero M, Anoman AD, Rosa-Téllez S, Ros R (2015) Lack of phosphoserine phosphatase activity alters pollen and tapetum development in Arabidopsis thaliana. Plant Sci 235:81-86

9. Liang M, Zhang P, Shu X, Liu C, Shu J (2013) Characterization of pollen by MALDI-TOF lipid profiling. Int J Mass Spectrom 334:13-18

10. Cigan AM, Singh M, Benn G, Feigenbutz L, Kumar M, Cho MJ, Svitashev S, Young J (2017) Targeted mutagenesis of a conserved anther-expressed $\mathrm{P} 450$ gene confers male sterility in monocots. Plant Biotechnol J 15:379-389

11. Dobritsa AA, Shrestha J, Morant M, Pinot F, Matsuno M, Swanson R, Moller BL, Preuss D (2009) CYP704B1 is a long-chain fatty acid omega-hydroxylase essential for sporopollenin synthesis in pollen of Arabidopsis. Plant Physiol 151:574-589

12. Li H, Pinot F, Sauveplane V, Werck-Reichhart D, Diehl P, Schreiber L, Franke R, Zhang P, Chen L, Gao Y, Liang W, Zhang D (2010) Cytochrome P450 family member CYP704B2 catalyzes the omega-hydroxylation of fatty acids and is required for anther cutin biosynthesis and pollen exine formation in Rice. Plant Cell 22:173-190

13. Yi B, Zeng F, Lei S, Chen Y, Yao X, Zhu Y, Wen J, Shen J, Ma C, Tu J, Fu T (2010) Two duplicate CYP704B1-homologous genes BnMs1 and BnMs2 are required for pollen exine formation and tapetal development in Brassica napus. Plant $\mathbf{J}$ 63:925-938

14. Hemmerly TE (1977) A ginseng farm in Lawrence County, Tennessee. Econ Bot 31:160-162

15. Kim YJ, Zhang D, Yang DC (2015) Biosynthesis and biotechnological production of ginsenosides. Biotechnol Adv 33:717-735

16. Kim YJ, Silva J, Zhang D, Shi J, Joo SC, Jang MG, Kwon WS, Yang DC (2016) Development of interspecies hybrids to increase ginseng biomass and ginsenoside yield. Plant Cell Rep 35:779-790

17. Kim YJ, Jang MG, Zhu L, Silva J, Zhu X, Sukweenadhi J, Kwon WS, Yang DC, Zhang D (2015) Cytological characterization of anther development in Panax ginseng Meyer. Protoplasma 253:1111-1124

18. Silva J, Kim YJ, Xiao D, Sukweenadhi J, Hu T, Kwon WS, Hu J, Yang DC, Zhang D (2017) Cytological analysis of ginseng carpel development. Protoplasma 254:1909-1922

19. Yu NY, Wagner JR, Laird MR, Melli G, Rey S, Lo R, Dao P, Sahinalp SC, Ester M, Foster LJ, Brinkman FS (2010) PSORTb 3.0: improved protein subcellular localization prediction with refined localization subcategories and predictive capabilities for all prokaryotes. Bioinformatics 26:1608-1615

20. Small I, Peeters N, Legeai F, Lurin C (2004) Predotar: a tool for rapidly screening proteomes for $\mathrm{N}$-terminal targeting sequences. Proteomics 4:1581-1590

21. Arnold J, Bordoli L, Kopp J, Schwede T (2006) The SWISSMODEL Workspace. a web-based environment for protein structure homology modeling. Bioinformatics 22:195-201

22. Kyte J, Doolittle RF (1982) A simple method for displaying the hydropathic character of a protein. J Mol Biol 157:105-132

23. Geourjon C, Deleage G (1995) SOPMA: significant improvements in protein secondary structure prediction by consensus prediction form multiple alignments. Comput Appl Biosci 11:681-684

24. Gasteiger E, Hoogland C, Gattiker A, Duvaud S, Wilkins MR, Appel RD, Bairoch A (2005) Protein identification and analysis tools on the ExPASy server. In: Walker JM (ed) The proteomics protocols handbook. Humana Press, Totowa, pp 571-607

25. Betchtold N, Pelletier G (1998) In planta Agrobacterium-mediated transformation of adult Arabidopsis thaliana plants by vacuum infiltration. In: Martinez-Zapater JM, Salinas J (eds) Arabidopsis protocols. Springer, New York, pp 259-266

26. Scheider CA, Rasband WS, Eliceiri KW (2012) NIH Image to Image J: 25 years of image analysis. Nat Methods 9:671-675

27. Li N, Zhang DS, Liu HS, Yin CS, Li XX, Liang WQ, Yuan Z, Xu B, Chu HW, Wang J, Wen TQ, Huang H, Luo D, Ma H, Zhang DB (2006) The rice tapetum degeneration retardation gene is required for tapetum degradation and anther development. Plant Cell 18:2999-3014

28. Igersheim A, Cichocki O (1996) A simple method for microtome sectioning of prehistoric charcoal specimens, embedded in 2-hydroxyethyl methacrylate (HEMA). Rev Palaeobot Palynol 192:389-393

29. Beeckman T, Viane R (2000) Embedding thin plant specimens for oriented sectioning. Biotech Histochem 75:23-26

30. Zhang Y, Liang W, Shi J, Xu J, Zhang D (2013) MYB56 encoding a R2R3 MYB transcription factor regulates seed size in Arabidopsis thaliana. J Integr Plant Biol 55:1166-1178

31. Isaacson T, Kosma DK, Matas AJ, Buda GJ, He Y, Yu B, Pravitasari A, Batteas JD, Stark RE, Jenks MA, Rose JK (2009) Cutin deficiency in the tomato fruit cuticle consistently affects 
resistance to microbial infection and biomechanical properties, but not transpirational water loss. Plant J 60:363-377

32. Shi JX, Adato A, Alkan N, He Y, Lashbrooke J, Matas AJ, Meir S, Malitsky S, Isaacson T, Prusky D, Leshkowitz D, Schreiber L, Granell AR, Widemann E, Grausem B, Pinot F, Rose JKC, Rogachev I, Rothan C, Aharoni A (2013) The tomato SISHINE3 transcription factor regulates fruit cuticle formation and epidermal patterning. New Phytol 197:468-480

33. Peterson R, Slovin JP, Chen CA (2010) A simplified method for differential staining of aborted and non-aborted pollen grains. Int J Plant Biol 1:e13

34. Franke R, Briesen I, Wojciechowski T, Faust A, Yephremov A, Nawrath C, Schreiber L (2005) Apoplastic polyesters in Arabidopsis surface tissues - a typical suberin and a particular cutin. Phytochemistry 66:2643-2658

35. Greer S, Wen M, Bird D, Wu X, Samuels L, Kunst L, Jetter R (2007) The cytochrome P450 enzyme CYP96A15 is the midchain alkane hydroxylase responsible for formation of secondary alcohols and ketones in stem cuticular wax of Arabidopsis. Plant Physiol 145:653-667

36. Hofer R, Briesen I, Beck M, Pinot F, Schreiber L, Franke R (2008) The Arabidopsis cytochrome P450 CYP86A1 encodes a fatty acid omega-hydroxylase involved in suberin monomer biosynthesis. J Exp Bot 59:2347-2360

37. Le Bouquin R, Pinot F, Benveniste I, Salaun JP, Durst F (1999) Cloning and functional characterization of CYP94A2, a medium chain fatty acid hydroxylase from Vicia sativa. Biochem Biophys Res Commun 261:156-162

38. Wellesen K, Durst F, Pinot F, Benveniste I, Nettesheim K, Wisman E, Steiner-Lange S, Saedler H, Yephremov A (2001) Functional analysis of the LACERATA gene of Arabidopsis provides evidence for different roles of fatty acid omega-hydroxylation in development. Proc Natl Acad Sci USA 98:9694-9699

39. Zhang W, Sun Y, Timofejeva L, Chen C, Grossniklaus U, Ma $\mathrm{H}$ (2006) Regulation of Arabidopsis tapetum development and function by DYSFUNCTIONAL TAPETUM1 (DYT1) encoding a putative Bhlh transcription factor. Development 133:3085-3095

40. Cabello-Hurtado F, Batard Y, Salaun JP, Durst F, Pinot F, WerckReichhart D (1998) Cloning, expression in yeast, and functional characterization of CYP81B1, a plant cytochrome P450 that catalyzes in-chain hydroxylation of fatty acids. J Biol Chem 273:7260-7726

41. Kandel S, Sauveplane V, Olry A, Diss L, Benveniste I, Pinot F (2006) Cytochrome P450-dependent fatty acid hydroxylases in plants. Phytochem Rev 5:359-372

42. Zhang J, Zhang B, Yang D, Dong W, Yang W, Li Q, Zeng L, Wang J, Wang L, Hicks LM, He Z (2011) Two Arabidopsis cytochrome P450 monooxygenases, CYP714A1 and CYP713A2, function redundantly in plant development through gibberellin deactivation. Plant J 67:342-353

43. Werck-Reichhart D, Feyereisen R (2000) Cytochromes P450: a success story. Genome Biol 1:REVIEWS3003

44. Sanders PM, Bui AQ, Weterings K, McIntire KN, Hsu YC, Lee PY, Truong MT, Beals TP, Golberg RB (1999) Anther developmental defects in Arabidopsis thaliana male sterile mutants. Sex Plant Reprod 11:297-322

45. Shi JX, Malitsky S, De Oliveira S, Branigan C, Franke RB, Schreiber L, Aharoni A (2011) SHINE transcription factors act redundantly to pattern the archetypal surface of Arabidopsis flower organs. PLoS Genet 7:e1001388

46. Kerstiens GE (1996) Plant cuticles: an integrated functional approach. BIOS Scientific Publishers, Oxford

47. Jeffree CE (2006) The fine structure of the plant cuticle. In: Riederer M, Muller C (eds) Biology of the plant cuticle. Blackwell Publishers Ltd, Oxford, pp 11-25
48. Riederer M, Muller C (2006) Biology of the plant cuticle. Blackwell Oxford, Oxford

49. Koch K, Ensikat HJ (2008) The hydrophobic coatings of plant surfaces: epicuticular wax crystals and their morphologies, crystallinity and molecular self-assembly. Micron 39:759-772

50. Samuels L, Kunst L, Jetter R (2008) Sealing plant surfaces: cuticular wax formation by epidermal cells. Annu Rev Plant Biol 59:683-707

51. Ahlers F, Bubert H, Steuernage S, Wiermann R (2000) The nature of oxygen in sporopollenin from the pollen of Typha angustifolia L. Zeitschrift für Naturforschung C 55:129-136

52. Ariizumi T, Toriyama K (2011) Genetic regulation of sporopollenin synthesis and pollen exine development. Annu Rev Plant Biol 62:437-460

53. Chen W, Yu XH, Zhang K, Shi J, De Oliveira S, Schreiber L, Shanklin J, Zhang D (2011) Male Sterile2 encodes a plastid-localized fatty acyl carrier protein reductase required for pollen exine development in Arabidopsis. Plant Physiol 157:842-853

54. Dobritsa AA, Lei Z, Nishikawa S, Urbanczyk-Wochniak E, Huhman DV, Preuss D, Sumner LW (2010) LAP5 and LAP6 encode anther-specific proteins with similarity to chalcone synthase essential for pollen exine development in Arabidopsis. Plant Physiol 153:937-955

55. Dobritsa AA, Geanconteri A, Shrestha J, Carlson A, Kooyers N, Coerper D, Urbanczyk-Wochniak E, Bench BJ, Sumner LW, Swanson R, Preuss D (2011) A large-scale genetic screen in Arabidopsis to identify genes involved in pollen exine production. Plant Physiol 157:947-970

56. Domínguez E, Mercado JA, Quesada MA, Heredia A (1999) Pollen sporopollenin: degradation and structural elucidation. Sex Plant Reprod 12:171-178

57. Grienenberger E, Kim SS, Lallemand B, Geoffroy P, Heintz D, Souza Cde A, Heitz T, Douglas CJ, Legrand M (2010) Analysis of TETRAKETIDE $\alpha$-PYRONE REDUCTASE function in Arabidopsis thaliana reveals a previously unknown, but conserved, biochemical pathway in sporopollenin monomer biosynthesis. Plant Cell 22:4067-4083

58. Guilford WJ, Schneider DM, Labovitz J, Opella SJ (1988) High resolution solid state 13C NMR spectroscopy of sporopollenins from different plant taxa. Plant Physiol 86:134-136

59. Kim SS, Grienenberger E, Lallemand B, Colpitts CC, Kim SY, Souza Cde A, Geoffroy P, Heintz D, Krahn D, Kaiser M, Kombrink E, Heitz T, Suh DY, Legrand M, Douglas CJ (2010) LAP6/ POLYKETIDE SYNTHASE A and LAP5/POLYKETIDE SYNTHASE B encode hydroxyalkyl $\alpha$-pyrone synthases required for pollen development and sporopollenin biosynthesis in Arabidopsis thaliana. Plant Cell 22:4045-4066

60. Shi J, Cui M, Yang L, Kim YJ, Zhang D (2015) Genetic and biochemical mechanisms of pollen wall development. Trends Plant Sci 20:741-753

61. Wang R, Dobritsa AA (2018) Exine and aperture patterns on the pollen surface: their formation and roles in plant reproduction. Annu Plants Rev 1:1-40

62. Wiermann R, Ahlers F, Schmitz-Thom I. Sporopollenin. In: A Stenbüchel, M Hofrichter (eds) Biopolymers. Wiley-VCH Verlag, Berlin, pp 209-227.

63. Wang K, Guo ZL, Zhou WT, Zhang C, Zhang ZY, Lou Y, Xiong SX, Yao XZ, Fan JJ, Zhu J, Yang ZN (2018) The regulation of sporopollenin biosynthesis genes for rapid pollen wall formation. Plant Physiol 178:283-294

64. Aarts MG, Hodge R, Kalantidis K, Florack D, Wilson ZA, Mulligan BJ, Stiekema WJ, Scott R, Pereira A (1997) The Arabidopsis MALE STERILITY 2 protein shares similarity with reductases in elongation/condensation complexes. Plant J 12:615-623

65. de Azevedo SC, Kim SS, Koch S, Kienow L, Schneider K, McKim SM, Haughn GW, Kombrink E, Douglas CJ (2009) A novel fatty 
Acyl-CoA synthetase is required for pollen development and sporopollenin biosynthesis in Arabidopsis. Plant Cell 21:507-525

66. Choi H, Jin JY, Choi S, Hwang JU, Kim YY, Suh MC, Lee Y (2011) An ABCG/WBC-type ABC transporter is essential for transport of sporopollenin precursors for exine formation in developing pollen. Plant J 65:181-193
Publisher's Note Springer Nature remains neutral with regard to jurisdictional claims in published maps and institutional affiliations. 